\title{
A Comparative Evaluation and Utilization of Entrapped Bacillus sp. (Gen Bank MN 243657) and Pseudomonas aeruginosa SU-1 in Poultry Waste Degradation ${ }^{\dagger}$
}

\author{
Sree Lakshmi ${ }^{1}$, Sruthi S. ${ }^{1}$, S. Dhiva ${ }^{1, *}$ \\ 1 Department of Microbiology, Calicut university, Kerala, India \\ 2 Department of Microbiology, Sree Narayana College, Alathur, Palakkad Dist, Kerala, India \\ * Correspondence: dhivasoju@gmail.com; \\ $\dagger$ Presented at International e-Conference on Bioengineering for Health and Environment (ICBHE 2020)
}

Received: 5.07.2020; Revised: 10.07.2020; Accepted: 12.07.2020; Published: 15.07.2020

\begin{abstract}
Bacillus sp. (Genbank MN243657) was obtained from the Center for Bioscience and Nanoscience Research, and $P$. aeruginosa SU-1 were used in this study. Initially, biomass was optimized for the incubation period, $\mathrm{pH}$, and temperature, following biomass optimization with RSM. The obtained organisms were able to produce keratinase, which was found to be a 64 KDa protein and $56 \mathrm{KDa}$. Now the biomass produced using the optimized condition was immobilized and checked for its ability to degrade keratinase, and efficiency was compared. Immobilized $P$. aeruginosa SU-1 was degrading keratin and feather better than Bacillus sp. (Genbank MN243657). It was found to reduce featherweight by $57.3 \%$ and $41 \%$. Hence it was found that both the immobilized bacterium can be used for poultry waste treatment, and P. aeruginosa SU-1 was more efficient than Bacillus sp. (Genbank MN243657).
\end{abstract}

Keywords: Pseudomonas aeruginosa SU-1; Bacillus sp. (Genbank MN243657); Keratinase;

Biomass; Feather Degradation.

(C) 2020 by the authors. This article is an open-access article distributed under the terms and conditions of the Creative Commons Attribution (CC BY) license (https://creativecommons.org/licenses/by/4.0/).

\section{Funding}

This research received no external funding.

\section{Acknowledgments}

This research has no acknowledgment.

\section{Conflicts of Interest}

The authors declare no conflict of interest. 